\title{
Monitoring by HPLC of Chamomile Flavonoids Exposed to Rat Liver Microsomal Metabolism
}

\author{
Georg Petroianu ${ }^{1}$, Éva Szőke ${ }^{2}$, Huba Kalász ${ }^{3}$, Péter Szegi ${ }^{4}$, Rudolf Laufer ${ }^{3}$, Bernadett Benkő ${ }^{5}$, \\ Ferenc Darvas ${ }^{6}$ and Kornélia Tekes ${ }^{*}, 4$
}

\author{
${ }^{I}$ Department of Cell Biology, Florida International University, Miami, FL, USA \\ ${ }^{2}$ Department of Pharmacognosy, Semmelweis University, Budapest, Hungary \\ ${ }^{3}$ Department of Pharmacology and Pharmacotherapy, Semmelweis University, Budapest, Hungary \\ ${ }^{4}$ Department of Pharmacodynamics, Semmelweis University, 1089 Budapest, Nagyvárad tér 4, Hungary \\ ${ }^{5}$ Division of Pharmacology and Drug Safety, Richter Gedeon Rt. Budapest, Hungary \\ ${ }^{6}$ CommInnex Zrt., Budapest, Hungary
}

\begin{abstract}
Three major flavonoid chamomile components (quercetin, apigenin-7-O-glucoside and rutin) were subjected to oxidative metabolism by cytochrome P-450 of rat liver microsomal preparations. Changes over time in their respective concentrations were followed using reversed-phase HPLC with UV detection. No clean-up had to be applied as only the specific flavonoid had to be separated from the background components originating from the rat liver microsome.

Neither the concentration of apigenin-7-O-glucoside nor that of the diglycoside rutin decreased during one hour of exposure to rat microsomal treatment. In contrast, the concentration of quercetin, a lipophilic aglycon, decreased.

Our analytical HPLC results complement the in silico calculated lipophilicity $(\log \mathrm{P})$ of these compounds; the relatively high lipophilicity of quercetin appears to predispose it to oxidative metabolism in order to decrease its fat solubility. In contrast the much less lipophilic compounds apigenin-7-O-glucoside and rutin were resistant in vitro to microsomal treatment.
\end{abstract}

Keywords: Microsomal treatment, cytochrome P-450 dependent oxidation, HPLC, quercetin, apigenin-7-O-glucoside, rutin.

\section{INTRODUCTION}

Chamomile is one of the oldest and best known favourites amongst medicinal herbs and its position as a therapeutical plant with multiple uses is well established. The positive effects derived from chamomile use are related to the presence of its numerous flavonoid constituents. Regarding their core structure many of these constituents are either flavone- (apigenin, luteolin) or flavonol- derivatives (quercetin, patuletin, isorhamnetin) [1]. They appear in various forms such as aglyca, mono- and diglycosides, and/or acyl-derivatives [2].

Some of these constituents have been directly associated with specific therapeutic effects; luteolin and the quercetin aglyca for instance have demonstrated protective and delaying effects on the development of diabetic complications [3].

Furthermore apigenin and its -7-O-glucoside derivative are among the most important therapeutic flavonoids; their spasmolytic and antiphlogistic effects are especially prominent [4], in addition to anti proliferative and apoptotic effects in various human cancer cell lines [5].

*Address correspondence to this author at the Department of Pharmacodynamics, Semmelweis University, 1089 Budapest, Nagyvárad tér 4, Hungary; E-mail: drtekes@gmail.com
The presence of apigenin in chamomile is however a matter of some debate as its presence has not been proved unequivocally. Carle et al. [6] and Schreiber et al. [7] compared extracts derived from freshly collected wild plants with those obtained from greenhouse plants. They concluded that apigenin is not originally present in fresh chamomile, but the result of secondary enzymatic processes. This would explain the great differences in the reported ratios of apigenin and apigenin-7-O-glycoside in the literature, differences which might also be due to different harvesting methods and storage conditions used. Repčak and Martonfi [8] observed that the content of apigenin aglyca in various parts of the flower increases by polyploidization. In di- and tetraploid samples the amount of apigenin aglyca increased by about $15 \%$. According to both the European and Hungarian Pharmacopoeias [9] the content of apigenin-7-Oglucoside in the Matricaria flower should be at least $0,25 \%$. This content is measured by HPLC. The HPLC method is suitable for the determination of other flavones too, irrespective of their state of glycosylation and/or acylation [9-15].

Our aim was to establish whether any of the major matricaria components [quercetin, apigenin-7-O-glucoside and rutin] is subjected to hepatic oxidative microsomal metabolism. 
Table 1. Name, Chemical Structure, Molecular Size and Composition Calculated Value of Lipophilicity (logP) and Total Polar Surface Area (TPSA, in Angström) of Certain Flavonoids Derived from Chamomile

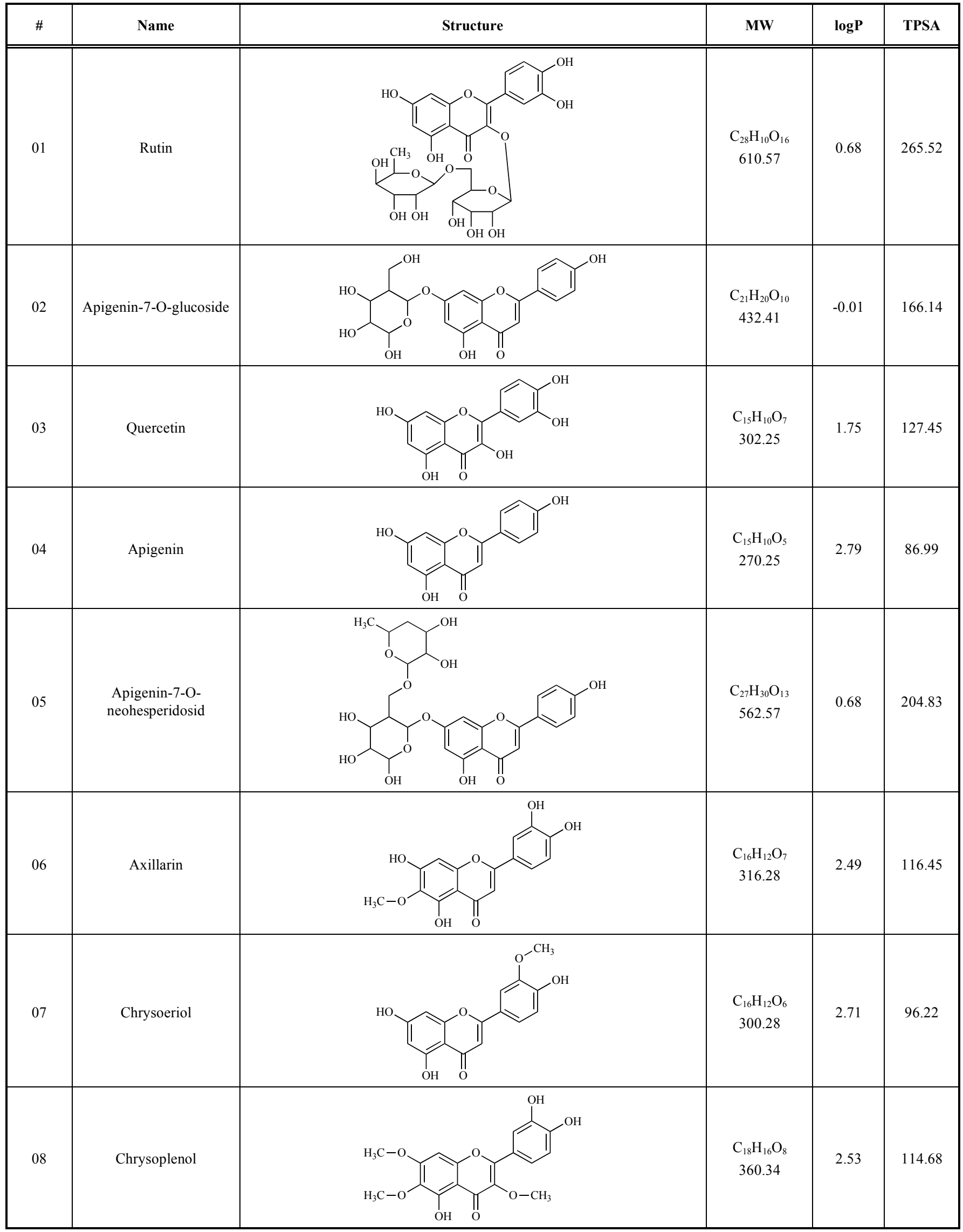




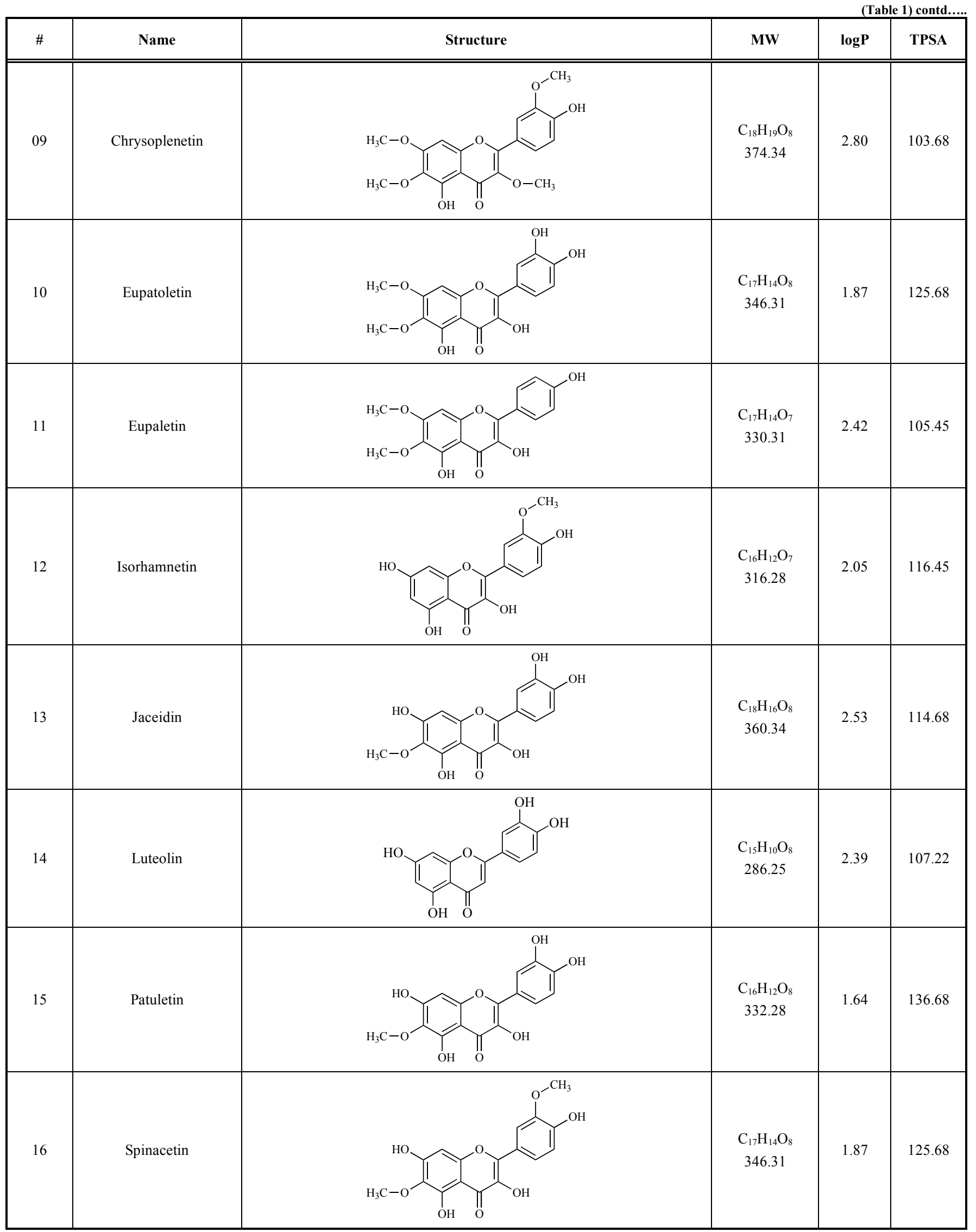




\section{EXPERIMENTAL}

Materials: HPLC grade acetonitrile, methanol and trifluoroacetic acid were purchased from Merck (Darmstadt, Germany). Water was double-distilled and deionized. Rutin, apigenin-7-O-glucoside and quercetin were purchased from Sigma-Aldrich (St. Louis, MO, USA). The chemical structures of rutin, apigenin-7-O-glucoside and quercetin are shown in Table 1. The Zorbax RX-C-18 column and precolumn were purchased from Kromat Kft. (Budapest, Hungary).

Microsomal Preparation: Quercetin, apigenin-7-Oglucoside and rutin $(25 \mu \mathrm{M}$, each) were incubated separately for $0,15,30,45$ and 60 minutes with rat liver microsome (Gedeon Richter Plc., Budapest, Hungary, Lot no. 081022, $\left.0.5 \mathrm{mg} \mathrm{mL}^{-1}\right)$ in $4 \mathrm{~mL}$ incubation medium also consisting of Tris- $\mathrm{HCl}$ buffer $\left(0.12 \mathrm{mM}, \mathrm{pH} 7.4\right.$ at $\left.37^{\circ} \mathrm{C}\right), \mathrm{MgCl}_{2}(5 \mathrm{mM})$, sodium phosphate $(6.25 \mathrm{mM})$, D-glucose-6-phosphate (5 $\mathrm{mM})$, D-glucose 6-phosphate dehydrogenase $\left(1 \mathrm{UmL}^{-1}\right)$, and the reduced form of nicotinamide adenine dinucleotide phosphate (NADPH, $0.5 \mathrm{mM}$ ). Parallel experiments were carried out using each substance (quercetin, apigenin-7-Oglucoside, rutin) in the buffered medium but without any Dglucose-6-phosphate, D-glucose 6-phosphate dehydrogenase and the reduced form of nicotinamide adenine dinucleotide phosphate. A control experiment that subjected the entire mixture to microsomal treatment (rat liver microsome, in the solution of Tris- $\mathrm{HCl}$ buffer at $\mathrm{pH} 7.4, \mathrm{MgCl}_{2}$, sodium phosphate, D-glucose-6-phosphate, D-glucose 6-phosphate dehydrogenase, and the reduced form of nicotinamide adenine dinucleotide phosphate) but without any substrate to be metabolized was also performed. Microsomal treatment was done using a rotating, thermostat-regulated water bath at $37^{\circ} \mathrm{C}$. Incubation with microsomal preparation was terminated after $0,15,30$ and 60 min respectively, by adding a 4-fold excess of methanol. Each experiment was performed in duplicate. Incubated samples were placed at $-20{ }^{\circ} \mathrm{C}$ for 10 minutes, and centrifuged using $2500 \mathrm{x}$ g at $4{ }^{\circ} \mathrm{C}$ (Sigma Laborzentrifugen, Osterode am Harz, Germany) and finally stored at $-80{ }^{\circ} \mathrm{C}$ before their reversed-phase HPLC measurement.

Chromatography: A JASCO made HPLC system was used that contained a solvent delivery system (PU 1580 Pump), degasser (DG-2080-54), an autoinjector (AS-2057 Plus), and a UV detector (UV-1575). Elution of rutin, apigenin-7-O-glucoside and quercetin was monitored at 257 $\mathrm{nm}$.

The samples were not subjected to any clean-up. Fifty $\mu \mathrm{L}$ of the samples were injected. The separation was done on a $250 \mathrm{~mm}$ x $4.6 \mathrm{~mm}$ I.D., $5-\mu \mathrm{m}$ particle size Zorbax RX-C-18 column protected by a $12.5 \mathrm{~mm}$ x $4.6 \mathrm{~mm}$, I.D. precolumn containing the same packing material. The mobile phases were acetonitrile-water 40:60, 35:65, 30:70, 25:75, 20:80, $15: 85$ and $10: 90$, and each mobile phase contained $0.1 \%$ of trifluoroacetic acid (TFA). The mobile phase flow rate was 1 $\mathrm{mL} \min ^{-1}$, the separations were done at ambient temperature $\left(24^{\circ} \mathrm{C} \pm 1^{\circ} \mathrm{C}\right)$. Chromatograms were electronically stored and evaluated by the use of Borwin 1.50 chromatography software (JMBS, Le Fontanil, France).

Calibration: Calibrations of the substances were done covering $0.5 \mu \mathrm{g} \mathrm{mL}^{-1}$ through $20 \mu \mathrm{g} \mathrm{mL}^{-1}$ range for quercetin, apigenin-7-O-glucoside and rutin.

Lipophilicity Calculations: The $\log \mathrm{P}$ value, and the total polar surface area (TPSA) were calculated using the Pallas program of CompuDrug [16,17].

\section{RESULTS}

The physico-chemical parameters of several chamomile flavonoids belonging to three major groups [aglycons (flavonoid compounds without any substituting sugar), monoglycosylated and diglycosylated] were calculated using the Pallas program. Chemical structures, molecular

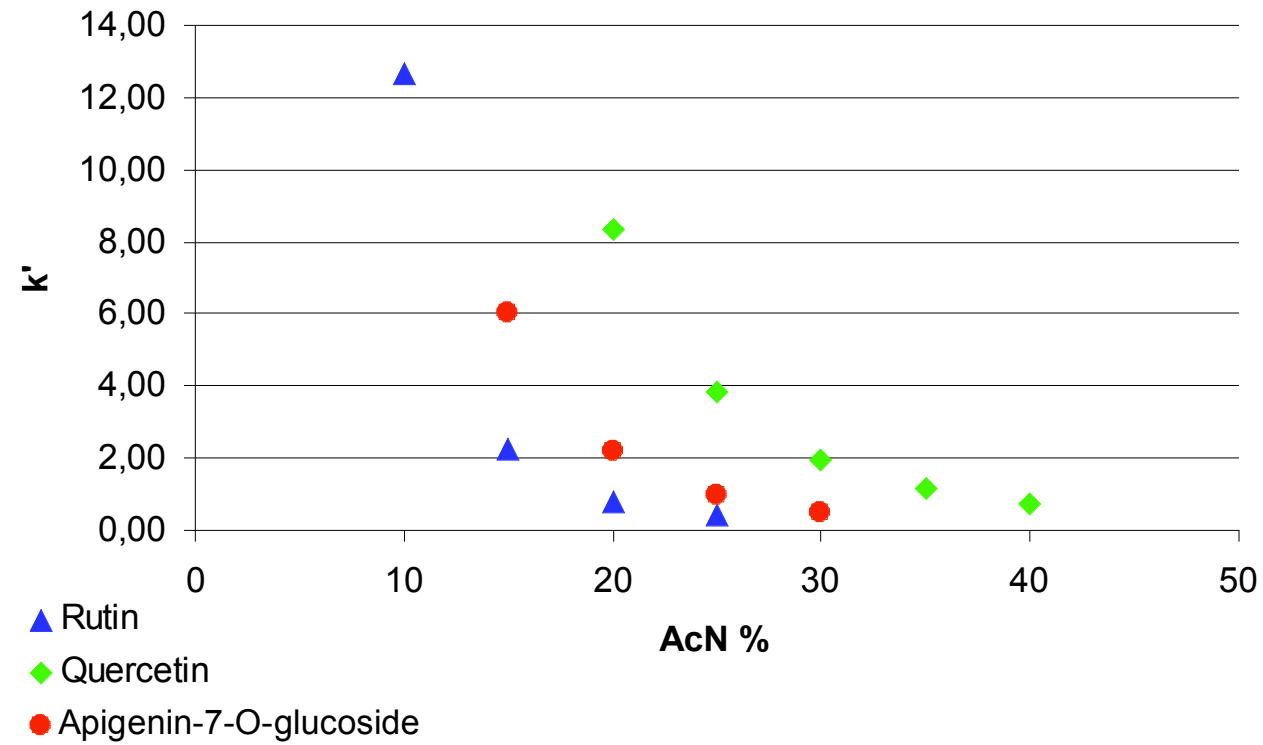

Fig. (1). The elution of quercetin, apigenin-7-O-glucoside and rutin are characterized by their $k$ ' values when using various compositions of the mobile phases. 
composition, molecular size, $\log \mathrm{P}$ and total polar surface area (TPSA in Angström) are given in Table 1. Flavonoid aglycons were rather lipophilic with a $\log \mathrm{P}$ value higher than 1.5 .

The mobile phase composition for HPLC of quercetin, apigenin-7-O-glucoside and rutin was optimized to avoid any interference with the background signal of the microsomal incubation medium. Different ratios of the organic modifier and water in the mobile phases were used, such as acetonitrile-water 50:50, 45:55, 40:60, 35:65, $30: 70,25: 75,20: 80,15: 85,10: 90$ (Fig. 1). Using the optimum mobile phase compositions, the peaks of quercetin, apigenin-7-O-glucoside and rutin eluted at 7.10, 7.72 and 7.73 minutes with the ratio of acetonitrile and water (30:70) for separation of qurcetin, apigenin-7-O-glucoside (20:80) and rutin (15:85), respectively. (Fig 2 , from left to right).

No interference of any one of the flavonoid compound peaks with those from the microsomal medium was found. Fig. (3) shows that calibration for all substances produced a straight line characterized by their respective parameters, $a, y_{0}$ and $R^{2}$ (from the equation of the straight line: $y=a x+y_{0}$ ), as shown in Table 2.
Molecular size (MW), lipophilicity $(\log \mathrm{P})$ and total polar surface area (TPSA) of several flavonoids were calculated using the Pallas Program of CompuDrug Inc. These values are given in Table $\mathbf{1}$.

\section{CONCLUSIONS}

Chamomile [the dried flower heads of Matricaria recutita L. (Chamomilla recutita [L.] Reuschert] has been used for centuries as a home remedy; its therapeutic value is well established as documented by the inclusion in numerous Pharmacopoeias.

In traditional medicine the plant is mostly used as chamomile tea, which is administered p.o. for alleviation of gastro-intestinal complaints [18]. Externally chamomile is applied on skin and/or mucous membranes at sites of minor inflammation, including the oral cavity and the gums (mouthwashes), the respiratory tract (inhalations), and the anal and genital areas (baths, ointments) [19,20].

The main constituents of chamomile are the essential oil and the flavone derivatives [21-23].

In vitro liver microsomal treatment of organic compounds serves as a model for the first pass effect of the
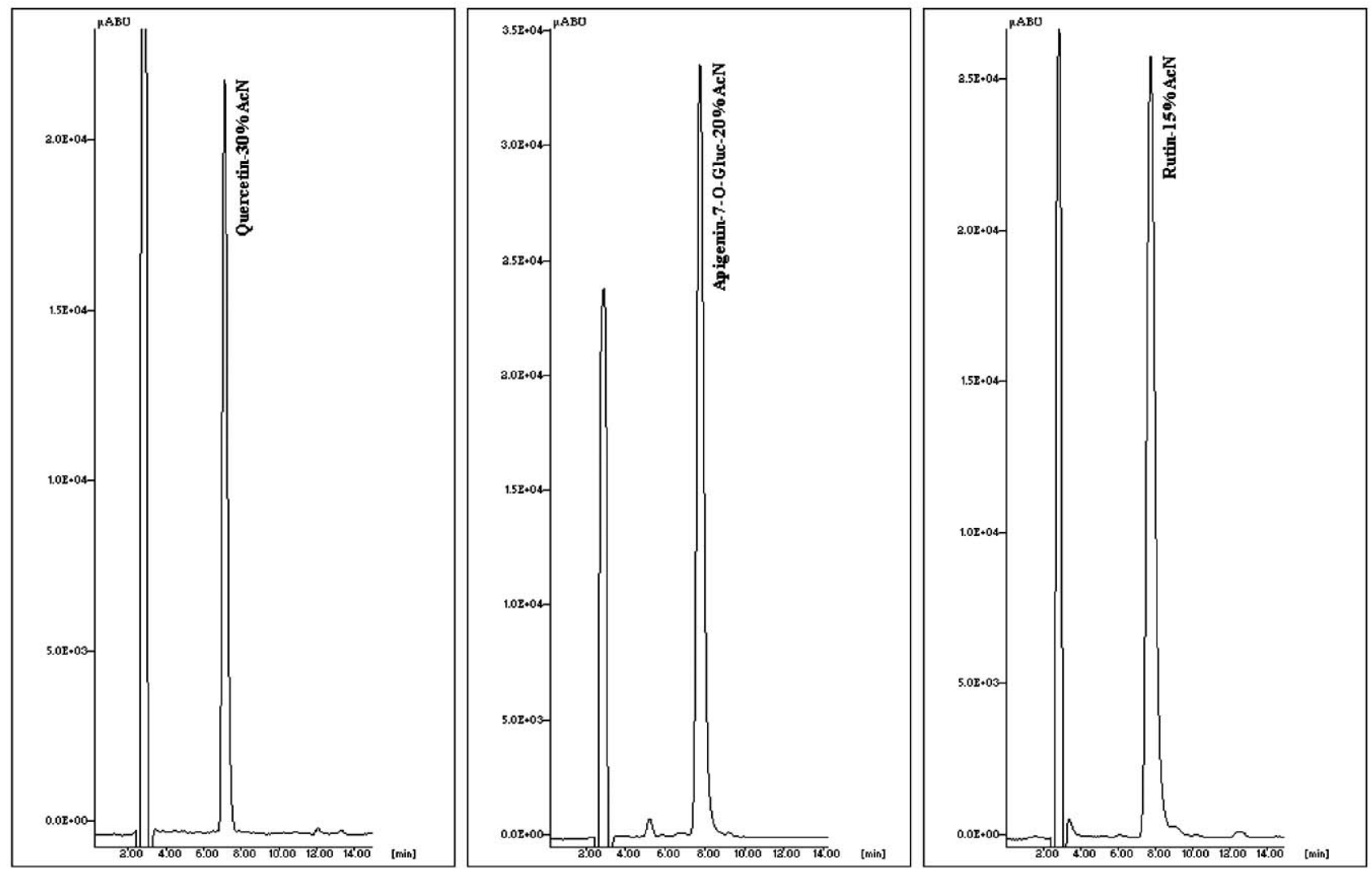

Fig. (2). Typical chromatograms of the microsomal medium spiked with the appropriate amount of quercetin, apigenin-7-O-glucoside and rutin in panels $\mathbf{a}, \mathbf{b}$ and $\mathbf{c}$ respectively. 


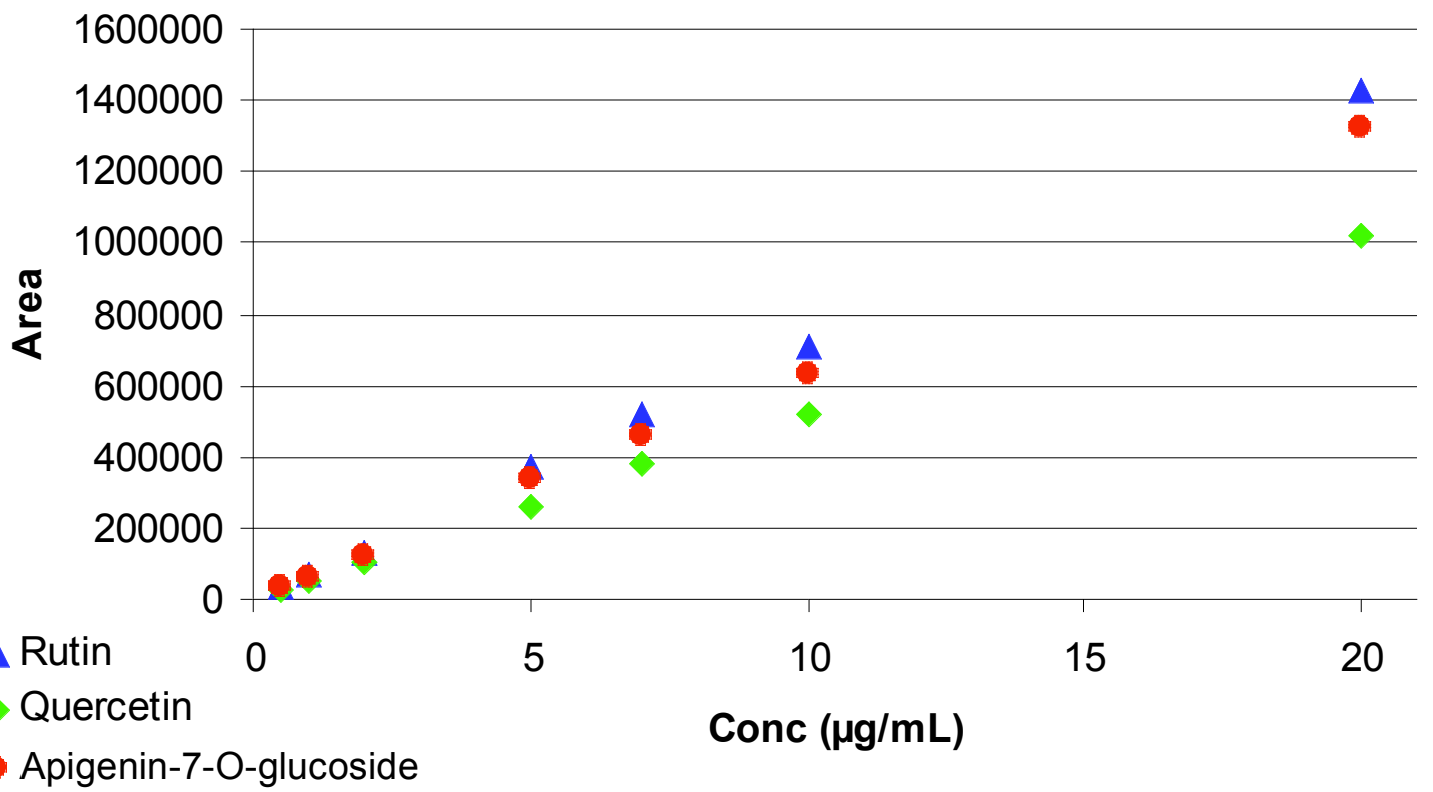

Fig. (3). Calibration curve for quercetin, apigenin-7-O-glucoside and rutin using the adequate mobile phase.

Table 2. Characteristics of the Calibration Lines $\left(y=a x+y_{0}\right)$ of RP-HPLC Quantitative Determination of Quercetin, Apigenin-7O-Glucoside and Rutin

\begin{tabular}{|l|c|c|c|}
\hline \multicolumn{1}{|c|}{ Compound } & a (Slope) & $\mathbf{y}_{\mathbf{0}}$ & $\mathbf{R}^{2}$ \\
\hline \hline Quercetin (03) & 51077 & 3701 & 0.9993 \\
\hline Apigenin-7-O-glucoside (02) & 66236 & 8101 & 0.9991 \\
\hline Rutin (01) & 71362 & 2246 & 0.9995 \\
\hline
\end{tabular}

liver in a living animal. Information may be obtained both on the putative fate of the compound in the body, and also the preferred way of administration. Liver microsomes generally metabolize xenobiotics (foreign compounds ingested) using oxidative metabolism via the cytochrome P-450 system. The lipophilicity of xenobiotics decreased via these reactions.
Fig. (4) compares the relative changes of the concentrations of quercetin, apigenin-7-O-glucoside and rutin during microsomal treatment. While the concentration of rutin and that of apigenin-7-O-glucoside remain unchanged, that of quercetin decreases.

The most lipophilic flavonoid, the aglycon quercetin undergoes cytochrome P-450-dependent microsomal

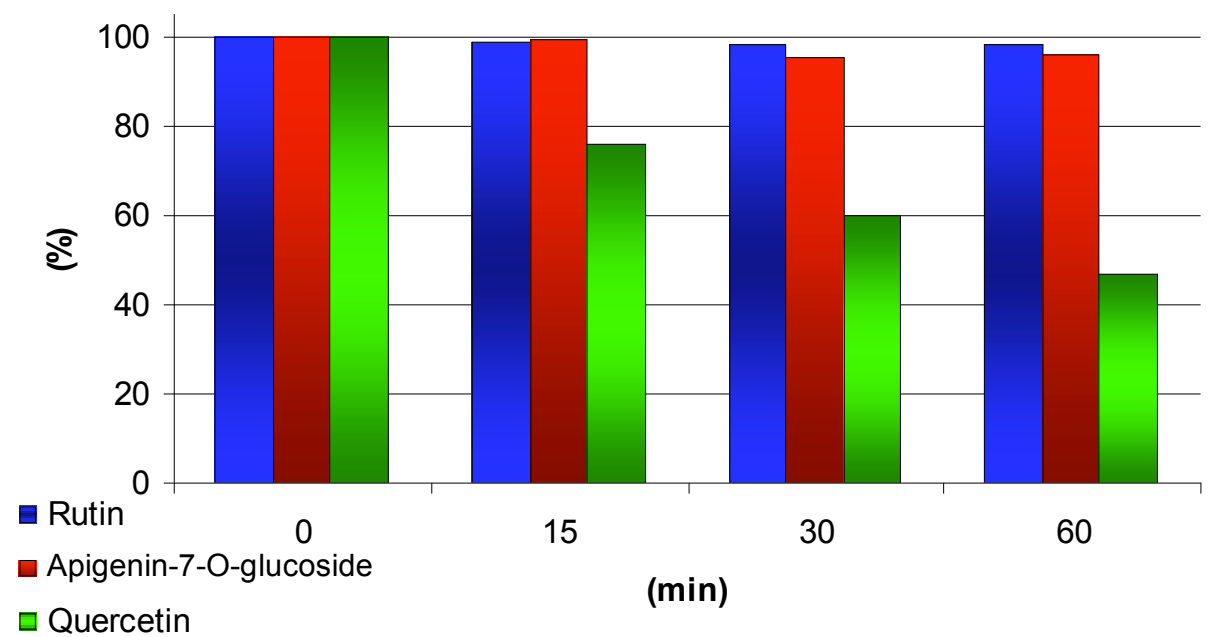

Fig. (4). Concentration of quercetin, apigenin-7-glucoside and rutin through the microsomal treatment at $0,15,30$ and 60 min of the treatment. 
metabolism, while the two less lipophilic compounds examined (apigenin-7-O-glucoside and rutin) were resistant to the effect of rat liver microsome (Fig. 4).

\section{REFERENCES}

[1] Carle, R.; Isaac, Q. Fortschritte in der Kamillenforschung in den Jahren 1974 bis 1984. Dtsch. Apoth. Ztg., 1985, 125(Suppl 1), 2-8.

[2] Švehliková, V.; Bennett, R.N.; Mellon, F.A.; Needs, P.W.; Piacente, S.; Kroon, P.A.; Bao, Z. Isolation, identification and stability of acylated derivatives of apigenin 7-O-glucoside from chamomile (Chamomilla recutita [L.] Rauschert). Phytochemistry, 2004, 65, 2323-2332.

[3] Kato, A.; Minoshima, Y.; Yamamoto, J.; Adachi, I.; Watson, A.A.; Nash, R.J. Protective effects of dietary chamomile tea on diabetic complications. J. Agricult. Food Chem., 2008, 56, 8206-8211.

[4] Petri, G. Gyógynövények és készítményeik a terápiában (Medicinal Plants and their Products in Therapy, in Hungarian), Galenus Publisher: Budapest, 2006.

[5] Srivastava, J.K.; Gupta, S. Anti proliferative and apoptotic effects of chamomile extract in various human cancer cells. J. Agricult Food Chem., 2007, 55, 9470-9478.

[6] Carle, R.; Dölle, B.; Müller, W.; Baummeister, U. Thermospray liquid-chromatography mass-spectrometry (tsp lc/ms) - analysis of acetylated apigenin-7-glucosides from chamomilla-recutita. Pharmazie, 1993, 48, 304-306.

[7] Schreiber, A.; Carle, R.; Reinhard, E. On the accumulation of apigenin in chamomile flowers. Planta Med., 1991, 56, 179-181.

[8] Repčak, M.; Martonfi, P. The variability pattern of apigenin glucosides in chamomilla-recutita diploid and tetraploid cultivars. Pharmazie, 1995, 50, 696-699.

[9] Pharmacopoea Hungarica, Ed. VIII. Tomus II., Medicina, Budapest, 2004, pp. 1944-1946, 2203-5.

[10] Carle, R. In Hagers Handbuch der Pharmazeutischen Praxis, 5th ed., Hänsel, R.; Keller, K.; Rimpler, H.; Schneider, G., Eds.; Springer: Berlin, 1992, 4, pp. 817-831.

[11] Kakasy, A.; Marczal, G.; Héthelyi, É.; Lemberkovics, É. Dracocephalum fajok mikromorfológiai és fitokémiai jellemzése
(Micromorphology and phytochemistry of certain Dracocephalum species, in Hungarian). Botanikai Közlemények, 2004, 91, 140.

[12] Papp, I.; Apáti, P.; Andrasek, V.; Blázovics, A.; Balázs, A.; Kursinszki, L.; Kite, G.C.; Houghton, P.J.; Kéry, Á. LC-MS analysis of antioxidant plant phenoloids. Chromatographia, 2004, 60, S93-S100.

[13] Kakasy, A.; Füzfai, Z.; Kursinszki, L.; Molnár-Perl, I.; Lemberkovics, É. Analysis of non-volatile constituents in Dracocephalum species by HPLC and GC-MS. Chromatographia, 2006, 63, S17-S22.

[14] Weber, B.; Herrmann, M.; Hartmann, B.; Joppe, H.; Schmidt, C.O.; Bertram, H.J. HPLC/MS and HPLC/NMR as hyphenated techniques for accelerated characterization of the main constituents in Chamomile (Chamomilla recutita [L.] Rauschert). Eur. Food Res. Technol., 2008, 226, 755-760.

[15] Szőke, É.; Kéry, Á.; Lemberkovics, É. Schweiz Pharmacognosy. Pharmacobotanical and Phytochemical Investigations of Plant Drugs. Semmelweis Kiadó, Budapest, 2009, (in press).

[16] Pallas Program: www.compudrug.com

[17] Molnár, L.; Keserü, G.M.; Papp, Á.; Gulyás, Z.; Darvas, F. A neural network based classification scheme for cytotoxicity predictions: validation on 30,000 compounds. Bioorg. Med. Chem. Lett., 2006, 16, 81037-81039.

[18] Franke, R.; Schilcher, H. Chamomile Industrial Profiles, CRC Press: Boca Raton, 2005

[19] Carle, R.; Isaac, O. Die Kamille - Wirkung und Wirksamkeit. Z Phytotherapie, 1987, 8, 67.

[20] Förster, C.F.; Süssmann, H.E.; Patzelt-Wenczler, R. Schweiz. Rundschau Med., 1996, 85, 1476.

[21] Schilcher, H. Die Kamilla - Handbuch für Ärzte, Apotheker und anderen Naturwissenschaftler, Wiss. Verlagsges, Stuttgart, Germany, 1987, p. 152.

[22] Szőke, E.; Máday, E.; Tyihák, E.; Kuzovkina, I.N.; Lemberkovics, É. New terpenoids in cultivated and wild chamomile (in vivo and in vitro). J. Chromatogr. B, 2004, 800, 231-238.

[23] Shikov, A.N.; Laakso, I.; Pozharitskaya, O.N.; Darman, H.J.D.; Makarov, V.G.; Tikhonov, V.P.; Hiltunen, R. Identification of spiroketal polyacetylenes as the main components of an oil extract of chamomile (Chamomilla recutita L. Rausch.) flowers. Planta Med., 2006, 72, 1026.

(C) A.A. El Maghraby; Licensee Bentham Open.

This is an open access article licensed under the terms of the Creative Commons Attribution Non-Commercial License (http://creativecommons.org/licenses/by$\mathrm{nc} / 3.0 /$ ) which permits unrestricted, non-commercial use, distribution and reproduction in any medium, provided the work is properly cited. 